
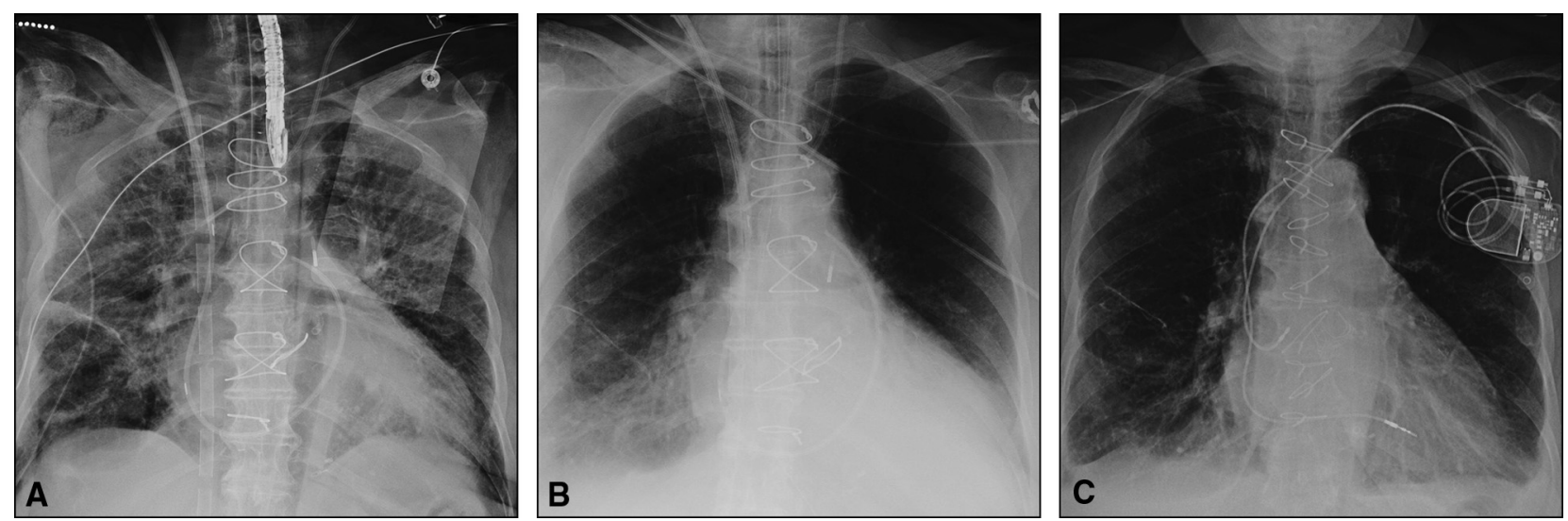

FIGURE 1. A, Chest radiograph after extracorporeal membrane oxygenation institution. B, Resolving pulmonary edema on extracorporeal membrane oxygenation support can be seen on the chest radiograph before aortic valve replacement. C, Chest radiograph before discharge from the hospital.

\section{References}

1. Hutter AM Jr, De Sanctis RW, Nathan MJ, Buckley MJ, Mundth ED, Daggett WM, et al. Aortic valve surgery as an emergency procedure. Circulation. 1970;41:623-7.

2. O'Brien SM, Shahian DM, Filardo G, Ferraris VA, Haan CK, Rich JB, et al. The Society of Thoracic Surgeons 2008 cardiac surgery risk models: part 2-isolated valve surgery. Ann Thorac Surg. 2009;88(1 Suppl):S23-42.
3. D’Ancona G, Pasic M, Buz S, Drews T, Dreysse S, Kukucka M, et al. Transapical transcatheter aortic valve replacement in patients with cardiogenic shock. Interact Cardiovasc Thorac Surg. 2012;14:426-30

4. Buchwald AB, Meyer T, Scholz K, Schorn B, Unterberg C. Efficacy of balloon valvuloplasty in patients with critical aortic stenosis and cardiogenic shock-the role of shock duration. Clin Cardiol. 2001;24:214-8.

\title{
Quantitative analysis of 3-dimensional aortic annular geometry: Implication for aortic root reimplantation
}

\author{
Liam P. Ryan, MD, ${ }^{\mathrm{a}}$ Melissa M. Levack, MD, ${ }^{\mathrm{b}}$ Joseph H. Gorman III, MD, ${ }^{\mathrm{b}}$ Robert C. Gorman, MD, \\ Rita C. Milewski, MD, PhD ${ }^{\mathrm{c}}$ and Joseph E. Bavaria, MD, ${ }^{\mathrm{c}}$ Charlotte, NC, and Philadelphia, Pa
}

The aortic valve reimplantation technique described and popularized by David and associates ${ }^{1}$ has demonstrated consistently excellent long-term outcomes during the past 2 decades in patients with aortic root dilatation but structurally normal, trileaflet aortic valves. The success of this operation, originally conceived as an alternative to aortic root replacement in patients with Marfan syndrome, has encouraged the broader application of derivative techniques to a number of distinct clinical scenarios, including bicuspid

\footnotetext{
From the Division of Cardiovascular Surgery, ${ }^{\text {a }}$ Sanger Heart and Vascular Institute, Carolinas Medical Center, Charlotte, NC; the Gorman Cardiovascular Research Group, ${ }^{\mathrm{b}}$ University of Pennsylvania School of Medicine, Philadelphia, Pa; and the Division of Cardiovascular Surgery, ${ }^{\mathrm{c}}$ University of Pennsylvania School of Medicine, Philadelphia, Pa.

Disclosures: Authors have nothing to disclose with regard to commercial support. Received for publication Dec 7, 2012; revisions received March 6, 2013; accepted for publication March 15, 2013; available ahead of print Dec 11, 2013.

Address for reprints: Joseph E. Bavaria, MD, Division of Cardiovascular Surgery, University of Pennsylvania School of Medicine, 3400 Spruce St, 6 Silverstein Pavilion, Philadelphia, PA 19104 (E-mail: Joseph.Bavaria@uphs.upenn.ed).

J Thorac Cardiovasc Surg 2014;147:1103-5 0022-5223/\$36.00

Copyright (C) 2014 Published by Elsevier Inc. on behalf of The American Association for Thoracic Surgery

http://dx.doi.org/10.1016/j.jtcvs.2013.03.046
}

aortic valve (BAV) syndrome with root dilatation and aortic insufficiency. ${ }^{2}$ Transposition of these valve-sparing techniques, all of which depend on restoration of functionally normal annular and leaflet geometry, to this geometrically unique patient population requires a thorough understanding of normal 3-dimensional BAV root complex geometry. ${ }^{3}$ To date, our collective understanding of root geometry in this patient population has largely been limited to 2-dimensional and anecdotal descriptors, which vary markedly among clinicians and institutions. ${ }^{4,5}$ In this study, we describe the rotational orientation of the aortic valve commissures in a cohort of patients with BAV without evidence of adverse remodeling. Our findings, which describe BAV root asymmetry in quantitative terms for the first time, have substantial implications for the ongoing evolution of valvesparing operative techniques in this patient population.

\section{MATERIALS AND METHODS}

Real time 3-dimensional echocardiographic data sets were acquired on 8 normal patients (tricuspid $\mathrm{n}=4$ and BAV $\mathrm{n}=4$ ) with an $\mathrm{iE}-33$ platform (Philips Medical Systems, Andover, Mass) equipped with a 2- to 7-MHz X7-2t transesophageal echocardiography matrix-array transducer. Inclusion criteria for both groups comprised maximum root diameter less than 

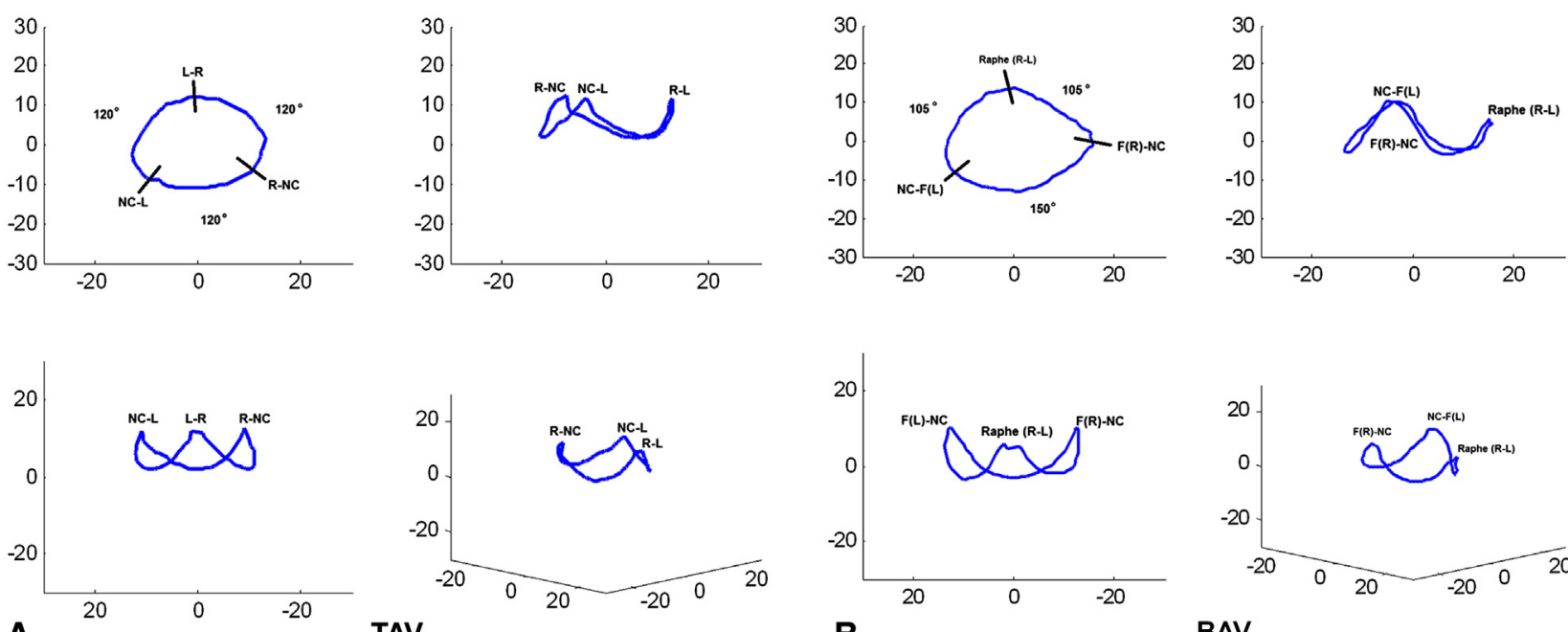

TAV

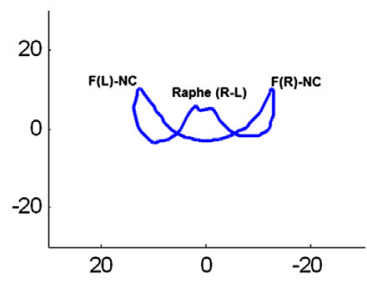

B

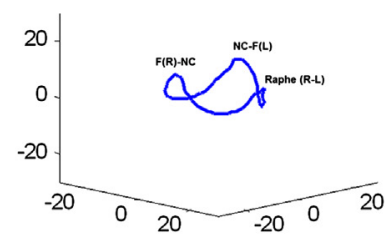

BAV

FIGURE 1. Three-dimensional hybrid reconstructions of 4 baseline tricuspid (TAV) annuli (A) and 4 baseline bicuspid (BAV) annuli (B). The natural shape of the normal tricuspid annulus assumes a relatively circular geometry, with symmetric spacing $\left(120^{\circ}: 120^{\circ}: 120^{\circ}\right)$ of the commissural peaks around the circumference of the aortic annulus. The baseline bicuspid annulus assumes a relatively eccentric geometry with both vertical and rotational asymmetry $\left(210^{\circ}: 150^{\circ}\right.$ or $\left.105^{\circ}: 105^{\circ}: 150^{\circ}\right) . L R$, Left-right commissural peak; $N C$ - $L$, noncoronary-left commissural peak; $R$ - $N C$, right noncoronary commissural peak; $R-L$, right-left commissural peak; $N C-F(L)$, noncoronary-fused left commissural peak; $F(R)$ - $N C$, fused right-noncoronary commissural peak; $F(L)-N C$, fused left-noncoronary commissural peak.

$3.8 \mathrm{~cm}$, no evidence of aortic stenosis, and aortic insufficiency graded no greater than mild by an experienced echocardiographer. An additional criterion for inclusion in the BAV patient cohort was confirmed right-left cusp fusion, the most common ( $>85 \%)$ morphologic variant of BAV. Each fullvolume data set was exported to an offline Echo-View 5.4 (TomTec Imaging Systems, Munich, Germany) software workstation for image postprocessing and quantitative analysis by means of a series of wellcharacterized custom algorithms.

\section{RESULTS}

The left, noncoronary, and right leaflets in the tricuspid cohort occupied $112.79^{\circ} \pm 7.49^{\circ}, 118.38^{\circ} \pm 17.70^{\circ}$, and $128.83^{\circ} \pm 20.10^{\circ}$ of the total annular circumference, respectively, corresponding conceptually to commissural peak orientations of $120^{\circ}: 120^{\circ}: 120^{\circ}$, as illustrated in Figure 1, A. In contrast, the noncoronary leaflet in the BAV cohort occupied $139.62^{\circ} \pm 16.43^{\circ}$ of the total annular circumference, while the fused leaflet occupied $220.38^{\circ} \pm$ $16.43^{\circ}$, corresponding conceptually to commissural peak orientations of $150^{\circ}: 210^{\circ}$, with the raphe located at the midpoint of the fused leaflet $\left(105^{\circ}: 105^{\circ}\right)$, as illustrated in Figure 1, $B$.

\section{DISCUSSION}

High resolution, 3-dimensional annular analysis reveals that aortic valve commissural peaks are distributed symmetrically around the annular circumference in trileaflet aortic roots. In contrast, the commissural peaks in patients with right-left fusion bileaflet aortic roots are highly asymmetric; in these patients, the fused leaflet occupies $210^{\circ}$ of the annular circumference and is bisected by the raphe $\left(105^{\circ}: 105^{\circ}\right)$, while the noncoronary leaflet occupies $150^{\circ}$ of the annular circumference. These findings have significant implications for aortic valve reimplantation in this patient population.

In the trileaflet variants of David aortic valve reimplantation procedures, the 3 commissural peaks are resuspended within the neosinus at evenly spaced rotational increments $\left(120^{\circ}: 120^{\circ}: 120^{\circ}\right)$. In view of our findings, it follows that analogous attempts to create a symmetrically suspended $\left(180^{\circ}: 180^{\circ}\right)$ neoroot in patients with BAV are potentially ill-advised, because this orientation does not reproduce native geometry. Our data suggest that the reproduction of native geometry requires that the principal commissures be spaced $210^{\circ}$ apart along the annular circumference and with the raphe located at the midpoint of the $210^{\circ}$ segment. Although many experienced surgeons advocate asymmetric repair strategies in the context of BAV, their recommendations are based largely on intraoperative observation and surgical judgment. Our data provide a reproducible and unambiguous geometric target for repair and may improve repair durability by replicating native leaflet geometry. Our findings are, however, based on a small sample size and are relevant to only the right-left fusion variant of BAV. Further studies are necessary both to assess the consistency of these findings and to assess the physiologic and clinical outcomes associated with these distinct repair strategies.

\section{References}

1. David TE, Feindel CM, Webb GD, Colman JM, Armstrong S, Maganti M. Longterm results of aortic valve-sparing operations for aortic root aneurysm. $J$ Thorac Cardiovasc Surg. 2006;132:347-54. 
2. Aicher D, Langer F, Kissinger A, Lausberg H, Fries R, Schäfers HJ. Valve-sparing aortic root replacement in bicuspid aortic valves: a reasonable option? J Thorac Cardiovasc Surg. 2004;128:662-8

3. Schäfers HJ, Langer F, Aicher D, Graeter T, Wendler O. Remodeling of the aortic root and reconstruction of the bicuspid aortic valve. Ann Thorac Surg. 2000;70: $542-6$
4. De Paulis R, De Matteis GM, Nardi P, Scaffa R, Bassano C, Chiariello C. Analysis of valve motion after the reimplantation type of valve-sparing procedure (David I) with a new aortic root conduit. Ann Thorac Surg. 2002;74:53-7.

5. Grande KJ, Cochran RP, Reinhall PG, Kunzelman KS. Mechanics of aortic valve incompetence: finite element modeling of aortic root dilatation. Ann Thorac Surg. 2000;69:1851-7.

\title{
Maintaining situational awareness in a cardiac intensive care unit
}

\author{
Daniel Engelman, MD, ${ }^{\mathrm{a}}$ Thomas L. Higgins, MD, ${ }^{\mathrm{b}}$ Rakesh Talati, MD, ${ }^{\mathrm{a}}$ and Jason Grimsman, MD, ${ }^{\mathrm{a}}$ \\ Springfield, Mass
}

We have developed a computerized system to assimilate pertinent real-time and historical patient data and present it in a user-oriented, clinically relevant form in our cardiac intensive care unit (ICU). This display is projected continuously above each patient's bed on a large liquid crystal display screen and updated in real time. This allows a provider team to simultaneously speak with a patient while reviewing all pertinent laboratory values, vital signs, ventilator settings, intake and output, hemodynamics, and vasoactive drug dosages, with trends shown in a graphic format. We believe this facilitates efficient, high-quality care and maintains optimal situational awareness.

Caring for patients in an ICU requires the assimilation of large amounts of continuously fluctuating data. The relationship between the various laboratory results, vital signs, medication dosages, and fluid shifts across time is an essential component to maintaining situational awareness of a patient's condition. This requires a practitioner to look at a huge variety of data, determine what is relevant, synthesize the data, and act on the analysis. In a modern ICU, this requires the detection and interpretation of cues from multiple dynamically changing data streams and the rapid adaptation to an evolving clinical situation. The need for a situational awareness tool in an ICU setting has been previously documented. ${ }^{1}$

Historically, situational awareness in many ICUs was maintained by means of an extensive handwritten flow sheet with hundreds of pieces of data manually added horizontally along a time axis. The clinician would assimilate how

\footnotetext{
From the Divisions of Cardiac Surgery ${ }^{\mathrm{a}}$ and Critical Care, ${ }^{\mathrm{b}}$ Baystate Medical Center, Springfield, Mass.

Disclosures: Daniel Engelman reports consulting and lecture fees from Cadence Pharmaceutical, and consulting fees from St. Jude Medical. All other authors have nothing to disclose with regard to commercial support.

Received for publication March 10, 2013; revisions received Oct 21, 2013; accepted for publication Oct 25, 2013; available ahead of print Dec 2, 2013.

Address for reprints: Daniel Engelman, MD, Division of Cardiac Surgery, Baystate Medical Center, 759 Chestnut St, Suite 4628, Springfield, MA 01107 (E-mail: daniel.engelman@baystatehealth.org).

J Thorac Cardiovasc Surg 2014;147:1105-6

$0022-5223 / \$ 36.00$

Copyright (c) 2014 by The American Association for Thoracic Surgery

http://dx.doi.org/10.1016/j.jtcvs.2013.10.044
}

changes in a given variable affected others across time. As electronic medical records have become standard, however, these handwritten flow sheets are being eliminated. This has necessitated ICUs to shift to computerized data gathering, which is often limited by screen size and by various menu-driven data sets of variable hospital information systems. Providers are at risk of losing situational awareness because the data are segregated onto different screens. In addition, it is difficult to assimilate all the data simultaneously into an overall clinical snapshot. Finally, the information requires logging into a nursing station computer, which may be out of the reach of the bedside clinician. There is little ability to talk to a patient or the rounding clinical team while simultaneously reviewing data from a password-protected information system.

As critical care technology has become more sophisticated, each device has fed its own monitoring system. This has resulted in a technology-centered design contributing to information overload. As an example, each of our postoperative cardiac surgical patients has separate monitors displaying vital signs, cardiac index, ventilator and intravenous pump settings, and laboratory results. There are also displays of the outputs from the drainage containers for chest tubes, urimeters, and nasogastric tubes. Finally, chest radiographs and continuous electrocardiographic monitoring are recorded. For a clinician to assimilate all this information accurately, this requires viewing multiple monitors and filtering large amounts of often superfluous data. A better system would be one that is user centered. ${ }^{2}$ This should be a presentation of relevant data that is goal directed, with only clinically relevant data included and presented to the clinician in a comprehensible and easily recognized form.

Our new system graphically displays large amounts of real-time patient data from multiple sources. The information is displayed over the patient's bed, allowing the clinical team to peruse key data while conversing in the patient's room during rounds (Figure 1). This placement also results in a more "patient-centric" and open discussion with family members. The graphic user interface is specifically designed to provide the maximal information for clinicians 